\title{
A RAMS analysis for a precision scale-up configuration of the 'Smart Street' pilot site: an industry 4.0 case study
}

\author{
Enrico Petritoli ${ }^{1}$, Fabio Leccese ${ }^{1}$, Martina Botticelli ${ }^{2}$, Stefano Pizzuti ${ }^{3}$, Francesco Pieroni ${ }^{3}$ \\ ${ }^{1}$ Science Department, Università degli Studi 'Roma Tre' Via Della Vasca Navale $n^{\circ} 84,00146$, Rome, Italy \\ ${ }_{2}^{2}$ Dipartimento di Ingegneria dell'Informazione Università Politecnica delle Marche, Via Brecce Bianche, 60131, Ancona, Italy \\ ${ }^{3}$ ENEA Italian National Agency for New Technologies, Energy and Sustainable Economic Development, Via Anguillarese 301, Rome, Italy
}

\section{ABSTRACT}

In order to develop a scale-up for a 'Smart Street' pilot site, we perform a RAMS analysis: the combination of Reliability Analysis and FMECA helps to identify the best configuration to scale up systems without incurring in marginally reliable configurations, allowing refining an Industry 4.0 Case Study.

\section{Section: RESEARCH PAPER}

Keywords: Smart Street; RAMS; reliability; prediction; FMECA; COTS

Citation: Enrico Petritoli, Fabio Leccese, Martina Botticelli, Stefano Pizzuti, Francesco Pieroni, A RAMS analysis for a precision scale-up configuration of the 'Smart Street' pilot site: an industry 4.0 case study, Acta IMEKO, vol. 8, no. 2, article 2, June 2019, identifier: IMEKO-ACTA-08 (2019)-02-02

Section Editor: Emiliano Sisinni, University of Brescia, Italy

Received May 31, 2018; In final form June 13, 2019; Published June 2019

Copyright: This is an open-access article distributed under the terms of the Creative Commons Attribution 3.0 License, which permits unrestricted use, distribution, and reproduction in any medium, provided the original author and source are credited.

Corresponding author: Fabio Leccese, e-mail: fabio.leccese@uniroma3.it

\section{INTRODUCTION}

The system called Smart Street is a public streetlighting line managed in an automatic, programmable way. Its general architecture is shown in Figure 1.

The first part of this document analyses the Smart Street pilot site system located at the ENEA Centre in Casaccia (Rome) from a qualitative point of view. The second part examines the scalability of the system to cover 5,000 streetlamps and some final considerations about architectural configurations.

This prediction approach, its trade-offs, and a study of the possible configurations are presented based on the military handbook MIL-HDBK-217, 'Reliability Prediction of Electronic Equipment' [1]-[4], appropriately modified to take account of new physical factors inherent in COTS components. A Failure Mode, Effects, and Criticality Analysis (FMECA) is also performed herein.

\subsection{The Smart Street system study}

In our study, a reliability analysis of the system is performed. Then, in order to preserve or increase the operating time in optimal conditions [5]-[7], the identification of some critical components (at the subsystem or component level) enables the implementation of an inventory stock in order to evaluate the cost effort in terms of time and labour related to maintenance [8]-[11].
The second analysis is a FMECA study [12]-[15], which, through logical sequences of operation, aims to mitigate the severity of the effects of a possible failure at the subsystem or component level [16]-[20].

A synthesis of the two previous methodologies gives us a sort of 'X-ray plate' of the system, highlighting the weak parts or subsystems. All this data is useful for evaluating the logistic efforts in terms of stock, intervention times, and possible maintenance.

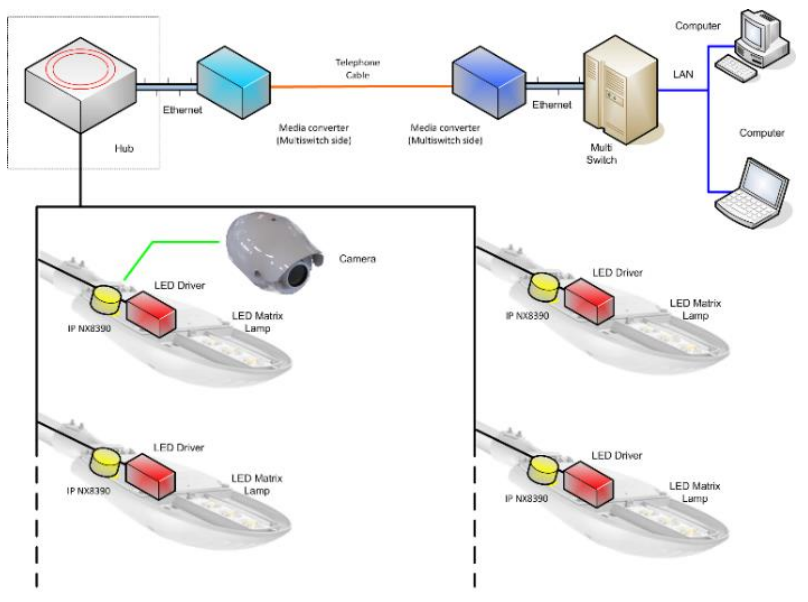

Figure 1. The general architecture of the Smart Street pilot site system. 


\section{THE RELIABILITY ANALYSIS: METHODS AND RESULTS}

Reliability predictions are an important tool for making design trade-off decisions and estimating the reliability of the design. They are often used for making initial product support decisions (such as how many spares are required to support the systems). Inaccurate predictions can lead to overly conservative designs and/or the procurement of excessive spare parts, resulting in added life cycle cost [21].

\subsection{The failure probability}

The failure of a component or system is an event whose occurrence can be examined in two different ways:

a. A casual event, whose causes remain substantially unknown and whose frequency is empirically observed;

b. The results of the chemical-physical degradation processes that evolve during the operation.

In the first case, the probability of failure is considered as the ratio between the occurrences of the observed failures and all executed tests [22]-[25].

The failure probability is calculated as a function of the observed failures, represented by the ratio:

$$
\lambda(t)=\frac{-\frac{d R(t)}{d t}}{R(t)} ;
$$

therefore, the expression of the reliability is:

$$
R(t)=e^{\int_{0}^{\infty} \lambda(t) d t} .
$$

The advantage is that the reliability of each item is easily studied and can be easily applied [26]. The disadvantage is that no information is supplied about the failure mode and therefore about the prognostic for each single item [27]-[28].

In the second case, the probability of failure is realised as the measure of uncertainty of the predictions; therefore, reliability can be calculated as a function of stress-strength relations, including the uncertainty in which the processes can be realised. In this case, a great amount of data and/or studies are needed [29].

We perform the reliability first by using the MIL-HDBK-217 handbook method, but the results are mitigated by factors that take into account degradation processes and environmental factors [30]-[35].

\subsection{The MIL-HDBK-217}

The MIL-HDBK-217 is the military handbook for the reliability prediction of electric and electronic equipment. It was developed in 1961 and has been frequently updated, with the most recent update in 1995 (see Table 2). The purpose of MILHDBK-217 is to establish consistent and uniform methods for estimating the inherent reliability of equipment and systems. By inherent, we mean the reliability of a mature and confident design [37]-[40].

MIL-HDBK-217 is a worldwide standard for performing reliability predictions. It includes a series of failure models based on empirical studies. These models virtually cover all electrical/electronic parts that are based on empirical studies. It also estimates 14 separate operational environments, such as ground fixed, airborne inhabited, etc. [41].

\subsection{The reasons for success of the MIL-HDBK-217}

The first handbook on reliability prediction, the 'Reliability Stress Analysis for Electronic Equipment' or TR-1100, was released by the Radio Corporation of America (RCA), one of the
Table 1. Overview of Reliability manuals.

\begin{tabular}{llc}
\hline Name & Application & Last Issue \\
\hline MIL-HDBK-217 & Mil/Commercial & 1995 \\
\hline Bellcore / Telcordia & Telecom & 2006 \\
\hline RDF 2000 & Telecom & 2000 \\
\hline SAE Rel. Pred. Meth. & Automotive & 1987 \\
\hline NTT Procedure & Telecom & 1985 \\
\hline Siemens SN29500 & Siemens Prop. & 1999 \\
\hline China 299B & Chinese Mil & 1998 \\
\hline PRISM & Mil/Commercial & 2000 \\
\hline
\end{tabular}

most important manufacturers of electronic components (especially vacuum tubes).

The handbook presents some important mathematical models for estimating electronic component failure rates and was the predecessor of what would be become the standard and a mandatory requirement for reliability prediction in the decades to come, MIL-HDBK-217 [4].

The first mathematical approach used in MIL-HDBK-217 is to estimate the failure rate by fitting a line through the field failure data. Soon after its introduction, all reliability predictions were based on this handbook, and all other sources of failure rates, such as those from independent experiments, gradually disappeared. The failure to use these other sources (see Tab. 1) was due to a very important fact: MIL-HDBK-217 was usually cited as a contractual document, preventing contractors from using other models or handbooks. In this sense, MIL-HDBK217 is strongly linked to the practical and active aspects of the industrial world and is part of the Industry 4.0 because the companies involved in the design and installation of efficient lamps managed by a remote control draw on the latest and most innovative technologies of the Internet of things (IoT) by means of a monitoring and/or control and feedback process fully integrated into the IoT itself.

\subsection{Two prediction methods}

In MIL-HDBK-217, there are two important prediction approaches: the Part Stress technique and the Parts Count technique. As the names imply, the Part Stress method requires knowledge of the stress levels of each component to determine their failure rates, while the Parts Count technique assumes average stress levels as a means of providing an early design estimate of the failure rates. Throughout this article, we use only this second method for the analysis [42].

In MIL-HDBK-217, reliability is usually expressed in failures in time (FiT): the number of failures that can be expected in one billion $\left(10^{9}\right)$ device hours of operations.

Typical factors used in determining a part's failure rate include a temperature factor $\left(\pi_{T}\right)$, power factor $\left(\pi_{P}\right)$, power stress factor $\left(\pi_{S}\right)$, quality factor $\left(\pi_{Q}\right)$, and environmental factor $\left(\pi_{E}\right)$ in addition to the base failure rate $\left(\lambda_{b}\right)$ method [43]-[44]. For example, the failure rate model for a resistor is as follows:

$$
\lambda_{g}=\lambda_{b} \cdot \pi_{T} \cdot \pi_{P} \cdot \pi_{S} \cdot \pi_{Q} \cdot \pi_{E}
$$

Ideally, the Parts Count technique is applied early in the design phase to determine that the predicted reliability is in the same 'ball park' as the reliability requirements. As more detailed design information becomes available, such as detailed circuit schematics, the predictions should be refined to reflect actual applied component stress levels [45]. 
This necessitates switching to the more detailed Part Stress reliability prediction methodology, which can result in significantly more labour hours for circuit analysis to compute the actual stress levels for each part application. In some cases, the Parts Count results are used as the final mean-time-betweenfailure (MTBF) estimator, despite that the results can be conservative because of the default stress levels assumed in the methodology. This situation sometimes leads to an excess of spare components [46].

In our analysis, we use the Parts Count method. It gives more conservative results than the Part Stress method, and it assumes the typical operating conditions of part complexity, environmental temperature, general electrical conditions, and operation conditions (called reference conditions).

The failure rate is calculated according to the Parts Count method,

$$
\lambda_{\text {TOT }}=\sum_{i=1}^{n} N_{i} \cdot\left(\lambda_{g} \cdot \pi_{Q}\right)_{i},
$$

where:

$\lambda_{g}$ is the failure rate of the generic part under environmental conditions

$N_{i}$ is the quantity of the part $i^{t h}$

$\pi_{Q}$ is the quality factor

$i$ is the number of part

As explained above, the MIL-HDBK-217 Parts Count method provides physically inconsistent data, so it is necessary to overcome the traditional approach to reliability analysis based on the failure rate or hazard rate, which is currently mature and has been consolidated in the international technical literature [47]-[53]. As mentioned, due to the extremely conservative feature of the Parts Count method, we have added the $\pi_{f f}$ corrective factor, so the final version of Equation (4) is now

$$
\lambda_{\text {TOT }}=\sum_{i=1}^{n} N_{i} \cdot\left(\lambda_{g} \cdot \pi_{Q} \cdot \pi_{c f}\right)_{i} .
$$

\subsection{COTS part and quality}

The quality factor and the corrective factor are critical for establishing the reliability of the system. Smart Street is composed entirely of commercial off-the-shelf (COTS) electronic components. The approach to establishing the quality of the component cannot therefore be the canonical one of MILHDBK-217 and therefore requires other considerations about the evolution of the failure and the environment [54].

The term 'COTS part' or 'component' is defined by the Society of Automotive Engineers (SAE) as 'An electronic component developed by a supplier for multiple customers, whose design and configuration are controlled by the supplier's or an industry specification.'

The use of COTS parts needs a special technical approach due to a lack of confidence in traceability, long-term performance, and new concerns affecting such parts, including compliance, counterfeiting, etc. [55].

A complete reliability analysis of these parts that properly evaluates risk and countermeasures is dependent on sufficient technological knowledge from prior usage, lessons learned, datasheets, modelling techniques, and manufacturer's information [56].

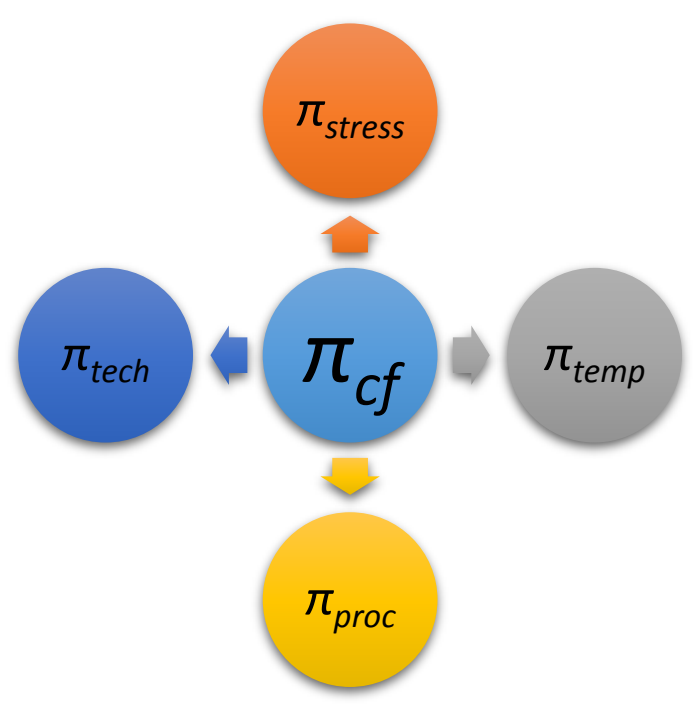

Figure 2. Corrective factor $\pi_{c f}$ composition

Specific studies should be made to evaluate the quality factor, with the primary concerns being:

- Part lifecycle and obsolescence monitoring, particularly for standard product lines;

- Use of historical performance data, long-term performance, and repeatable results;

- Lessons learned concerning a particular part type, part number, or manufacturer;

- The part's specific temperature constraints;

- Lot homogeneity;

- Procurement technique i.e. a controlled manufacturer's specification; and

- Counterfeit avoidance.

\subsection{The corrective factor $\pi_{c f}$}

The $\pi_{\mathrm{cf}}$ takes into account several parameters, including the technological factor, procedural factor, stress factor, and temperature factor [57] (see Figure 2). The complete expression is

$$
\pi_{c f}=\pi_{\text {tech }} \cdot \pi_{\text {proc }} \cdot \pi_{\text {temp }} \cdot \pi_{\text {stress }} .
$$

In specific detail, we have:

$\pi_{\text {tech }}$ - Technological Factor: MIL-HDBK-217 has so far remained behind regarding the technological capabilities of the individual electronic components since at the time of the last issue, it did not even imagine the rapid development of many manufacturing techniques and circuit integrations [58].

$\pi_{\text {proc }}$ - Procedural Factor: The general philosophy of the handbook is to examine 'all the possible types of electronic components in all possible conditions in all imaginable environments' [59]. For this reason, MIL-HDBK-217 is highly rigid and schematic. In other words, to work well, the method needs to 'freeze' or rather to give a picture of the current electronic technology [60]; to study all the details; and then, after careful evaluation and testing, to deliver the reliability calculation algorithm.

$\pi_{\text {temp }} \cdot \pi_{\text {stress }}$ - Stress and Temperature Factor: In its broadest sense, to define the electric and thermal stress of the component, the environment (and other local stress) in which it is placed is not sufficient to establish its reliability. 
Moreover, it is important the type and the components from which, the part in question is surrounded.

The $\pi_{\text {tech }}$ technological factor is composed of three other factors,

$$
\pi_{\text {tech }}=F_{\text {complex }}+F_{\text {confidence }}+F_{\text {homog }},
$$

where:

$F_{\text {complex }}$ - Complexity Factor: This parameter takes into account the class of the technological complexity of the component or subsystem.

$F_{\text {confidence }}$ - Confidence Factor: This parameter takes into account the duration of the production period of the component or subsystem and its length of service.

$F_{\text {bomog }}$ - Homogeneity Factor: This parameter takes into account the differences in production and the level of difference between the different production lots.

The $\pi_{\text {proc }}$ procedural factor is composed of three other factors,

$$
\pi_{\text {proc }}=F_{\text {hum }}+F_{\text {manufact }} \text {, }
$$

where:

$F_{\text {bum }}$ - Human Factor: This parameter takes into account any human-caused errors or imperfections of assembly.

$F_{\text {manufact }}$ - Manufacturer Factor: This parameter takes into account any errors or imperfections due to secondary processing techniques.

The $\pi_{\text {proc }}$ temperature factor is expressed as:

$$
\pi_{\text {temp }}=\int_{T_{0}}^{T_{t}} f_{T_{\text {degr }}}(T) d T .
$$

The function $f_{\text {Tdegr }}$ expresses the degradation mode of the component or the subsystem that evolves from the temperature $T_{0}$ up to the final temperature $T_{t}$, recording the trend and all the possible variations.

The $\pi_{\text {stress }}$ stress factor is expressed as:

$$
\pi_{\text {stress }}=\int_{t_{0}}^{t} f_{\text {Stress }}(t) d t \text {. }
$$

The function $f_{\text {Tdegr }}$ expresses the way in which the component or the subsystem is stressed or how much and how its operation moves from the ideal mode and approaches its critical limit [62].

The total corrective factor is now expressed as:

$$
\begin{aligned}
\pi_{c f}=\left(F_{\text {complex }}+\right. & \left.F_{\text {confidence }}+F_{\text {homog }}\right) \\
& \cdot\left(F_{\text {hum }}+F_{\text {manufact }}\right) \\
& \cdot\left[\int_{T_{0}}^{T_{t}} f_{T_{\text {degr }}}(T) d T\right] \\
& \cdot\left[\int_{t_{0}}^{t} f_{\text {Stress }}(t) d t\right] .
\end{aligned}
$$

Note that some elements of the function are not linear and in any case are not related to each other over time [63].

From a physical point of view, we can see the mathematical function as if many degradation processes act on the various components of the system in a completely independent way [64].

\subsection{Uncertainty and component degradation}

In this section, starting from the component degradation model, we define the limits and uncertainty criteria for determining the optimal value that meets or exceeds the maximum life threshold (expected life). We evaluate the level of degradation for the $i^{\text {th }}$ specimen for a time $\hat{t} \in[0, \infty)$ in a cycle of single use $\Psi_{i}=\left\{\psi_{i, 1}, \ldots, \psi_{i, Q}\right\}, Q \in \mathbb{N}$, then a set of random specimen variables $\Omega_{i}=\left\{\omega_{i, 1}, \ldots, \omega i, V\right\}, V \in \mathbb{N}$ that defines the bealth (degradation status) of the part, following a normal (Laplace-Gauss) distribution.

Now, we define the expected useful life (reliability) as the probability that the degradation at time $T_{\eta}$ reaches the theoretical failure threshold $\eta$ before time $\hat{t}$ is:

$$
P_{r}\left\{T_{\eta}<\hat{t}\right\}=P_{r}\left\{H\left(\hat{t} ; \Psi_{i}, \Omega_{i}\right)>\eta\right\}, \quad \forall i \in I .
$$

We consider a component with the following degradation path (which has been chosen because it is typical of such components):

$$
H_{i}\left(t, \Psi_{i}, \Omega_{i}\right)=\psi_{i, 1}+\omega_{i, 1} \cdot \hat{t}^{\psi_{i, 2}},
$$

where $\Psi_{i}=\left\{\psi_{i, 1}, \psi_{i, 2}\right\}$ and $\Omega_{i}=\left\{\omega_{i, 1}\right\}$, then:

$$
\begin{aligned}
& P_{r}\left\{T_{\eta}<\hat{t}\right\}=P_{r}\left\{\psi_{i, 1}+\omega_{i, 1} \cdot \hat{t}^{\psi_{i, 2}}>\eta\right\} \\
& P_{r}\left\{T_{\eta}<\hat{t}\right\}=P_{r}\left\{\omega_{i, 1}>\frac{\chi-\psi_{i, 1}}{\hat{t}^{\psi_{i, 2}}}\right\} .
\end{aligned}
$$

For a random specimen health variable, $\omega_{i, 1} \geq 0$, we evaluate the cumulative density function $F_{\omega_{i, 1}}$ :

$$
P_{r}\left\{T_{\eta}<\hat{t}\right\}=1-F_{\omega_{i, 1}}\left(\frac{\eta-\psi_{i, 1}}{\hat{t}^{\psi_{i, 2}}}\right) .
$$

We define the control time points as a time interval in which the performances of the component are checked (tested). Obviously, the component cannot be monitored continuously throughout the degradation process. Rather, it is checked at regular intervals.

Now, we evaluate the probability according to which, between the two control time points $(n-1) \tau$ and $n \tau$, the expected life $E_{L}$ is reached:

$$
\begin{aligned}
& P_{r}\left\{H_{i}\left((n-1) \tau ; \Psi_{i}, \Omega_{i}\right)\right\} \leq E_{L}<H_{i}\left(n \tau ; \Psi_{i}, \Omega_{i}\right), \\
& \forall n \in \mathbb{N} .
\end{aligned}
$$

So we define $T_{E_{L}}$ as:

$$
P_{r}\{(n-1) \tau\} \leq T_{E_{L}}<n \tau, \quad \forall n \in \mathbb{N} .
$$

The real failure threshold $H_{i}$ is reached before time point $n \tau$ only if it has satisfied the following condition:

$$
P_{r}\left\{H_{i}\left(n \tau ; \Psi_{i}, \Omega_{i}\right)>\eta_{i}\right\}=P_{r}\left\{T_{H_{i}}<n \tau\right\}, \quad i \in I .
$$

Moreover, assuming the degradation path is monotonic (typical of this kind complex systems), we have $E_{L}<H_{i}$ and $T_{E_{L}} \leq T_{H}$.

The probability that a failure happens at the specific time $n \tau$ after the degradation level of the $i^{\text {th }}$ component has reached the failure limit $(n-1) \cdot \tau \leq E_{L}<n \tau$ is: 
Table 2. Reliability analysis summary (baseline).

\begin{tabular}{|c|c|c|c|c|c|}
\hline Description & $\begin{array}{c}\lambda_{\mathrm{p}} \\
\text { in } \mathrm{F} /\left(10^{6} \mathrm{hrs}\right)\end{array}$ & $\boldsymbol{\sigma}$ & Q.ty & $\begin{array}{c}\lambda_{\mathrm{P}} \text { TOT } \\
\text { in } \mathrm{F} /\left(10^{6} \mathrm{hrs}\right)\end{array}$ & $\begin{array}{l}\text { MTBF } \\
\text { in hrs }\end{array}$ \\
\hline $\begin{array}{c}\text { Ethernet } \\
\text { (Multiswitch side) }\end{array}$ & 0.08 & 0.05728 & 1 & 0.08 & 12048192.8 \\
\hline $\begin{array}{l}\text { Media converter } \\
\text { (Multiswitch side) }\end{array}$ & 4.78 & 0.01047 & 1 & 4.78 & 209205.0 \\
\hline Telephone Cable & 0.07 & 0.00788 & 1 & 0.07 & 15384615.4 \\
\hline $\begin{array}{l}\text { Media converter } \\
\text { (Hub side) }\end{array}$ & 4.78 & 0.34634 & 1 & 4.78 & 209205.0 \\
\hline $\begin{array}{l}\text { Ethernet } \\
\text { (Hub side) }\end{array}$ & 0.08 & 0.06739 & 1 & 0.08 & 12048192.8 \\
\hline Hub & 11.60 & 0.00911 & 1 & 11.60 & 86206.9 \\
\hline Camera & 232.55 & 0.00084 & 1 & 232.55 & 4300.2 \\
\hline IP NX8390 & 5.41 & 0.01278 & 5 & 27.05 & 36968.6 \\
\hline LED Driver LE414 & 108.75 & 0.56069 & 5 & 543.77 & 1839.0 \\
\hline LED Lamp & 57.00 & 0.08015 & 5 & 285.00 & 3508.8 \\
\hline \multicolumn{4}{|c|}{ Total Reliability: $\lambda_{\text {тот }}$ in $\mathrm{F} /\left(10^{6} \mathrm{hrs}\right)$} & 1109,77 & \\
\hline \multicolumn{4}{|c|}{ (equivalent to) MTBF (RTotal) in hrs } & 901,09 & \\
\hline
\end{tabular}

$P_{r}\{P M$ at $n \tau\}=P_{r}\left\{T_{H_{i}}>n \tau,(n-1) \tau \leq T_{E_{L}}<n \tau\right\}$.

So, we define the uncertainty in the reliability assessment of the component $U_{\lambda}$ as:

$U_{\lambda}=H_{i}-E_{L}$.

\subsection{The baseline reliability analysis}

The baseline pilot system is presented in detail in Table 2. It consists of five street lamps (each complete with LED arrays, drivers, and an IP node), one of which is equipped with a camera [65]-[71]. Information on the health status of the street lamp, its consumption, and the camera data are sent to a hub, then the information is converted for transmission in the telephone network through two media converters. In the end, the information are sent to a multiswitch that sends them to users who request them [72]-[73]. The failure analysis of the baseline system returned a $\mathrm{MTBF}_{\text {TOT }}$ equal to 5,483 hours, which is equivalent to about 20 months of operation (with the lamps being active 10 hours per day) [74].

The most critical component is the LED driver, which alone gives around $50 \%$ of all FiTs of the system. It is the part that is most prone to failure and therefore the most likely candidate for an appropriate stock escort [75].

The analysis resulted in a value of $\mathrm{MTBF}_{\text {CAMERA }}$ equal to 4,300 hours, equivalent to about six months of uninterrupted operation. This seemingly low value is due to the fact that the camera is still prototypal, and updates, both software and hardware, are constantly made to it.

A critical component is certainly the hub which, in the face of a comforting $\mathrm{MTBF}_{\mathrm{HUB}}$ of 86,200 hours and in the case of catastrophic failure, should cause complete shutdown to all the sections of the lamp network [76]-[81].

\section{FMECA: METHOD AND RESULTS}

\subsection{Criteria}

The FMECA is a methodology designed to identify the potential failure modes for a product or process, to assess the risks associated with those failure modes, to rank the issues in terms of importance, and to identify and carry out corrective actions to address the most serious concerns [82].

In the FMECA, the entire system is examined on a functional level, and the effects of failures and malfunctions on the performance of the equipment are determined. The interface
Table 3. The Smart Street system: 'Level 1' criticalities (FMECA extract).

\begin{tabular}{llllll}
\hline & & & \\
& & &
\end{tabular}

circuits of the various subsystems, on the other hand, are analysed at the component level [83].

For each failure mode, the effect, cause, and ways of remedying the failure are studied, with particular attention to any recommendations for changing the project or prevention methods and the frequency at which the failure mode is observed (if possible) [84]-[88].

These results are used for identifying 'singular' faults (single point failure $[\mathrm{SPF}]$ ), critical elements, errors, and underestimations of the project and for checking, as far as possible, that all critical failure modes can be fully tested at the subsystem level during assembly [89]-[91]. In Table 3, we can see an extract of the FMECA tables. We have selected all the occurrences of Grade 1 faults (the most serious), i.e. those in which the failure of one system (or unit) can spread to other systems (or adjacent units). The table, for the sake of brevity, does not show all the columns of the FMECA. Rather, only the most interesting and coherent ones are presented.

\subsection{FMECA assumptions}

In the subsequent FMECA, the following presumptions are made:

- The total failure of the examined function is presumed;

- Only one failure mode is considered at a time (i.e. no correlated failures are taken into consideration, except as recommendations);

- The FMECA is performed at the function and unit levels, with the exception of interfaces that are analysed at the component level (wherever possible and opportune); and

- The probability of failure, which is the subject of a specific analysis, is not considered.

\subsection{Results}

The presumed failure mode reported in the FMECA tables is reported as a function of the worst fault i.e. the loss of the function of the main unit [92].

The Smart Street system has been examined in the form of a pilot system with a number of LED lamps reduced to five, one of which is equipped with a video camera. A possible increase or decrease in the number of the lamps without a camera does not significantly affect the philosophy of the approach to the reliability study of the overall system [93].

Note that, despite no part of the system is redundant, the system is quite resilient and not "damage sensitive". In fact, not 
Table 4. Configurations trade-offs.

\begin{tabular}{|c|c|c|c|c|}
\hline \multirow{2}{*}{$\begin{array}{c}\text { \# of } \\
\text { LED } \\
\text { Lamps }\end{array}$} & \multicolumn{2}{|c|}{$\begin{array}{l}\text { MTBF } \\
\text { in hrs }\end{array}$} & \multirow{2}{*}{$\Delta_{\mathrm{MTBF}}$} & \multirow{2}{*}{$\begin{array}{l}\Delta_{\mathrm{MTBF}} \\
\text { in \% }\end{array}$} \\
\hline & Single Hub & Multi-Hub & & \\
\hline 5 & 901.1 & 901.1 & 0.0000 & 0.0000 \\
\hline 10 & 452.5 & 454.9 & 2.3882 & 0.0053 \\
\hline 15 & 302.1 & 304.3 & 2.1329 & 0.0071 \\
\hline 20 & 226.8 & 228.6 & 1.8039 & 0.0080 \\
\hline 25 & 181.5 & 183.0 & 1.5415 & 0.0085 \\
\hline 50 & 90.8 & 91.7 & 0.8696 & 0.0096 \\
\hline 100 & 45.4 & 45.9 & 0.4596 & 0.0101 \\
\hline 150 & 30.3 & 30.6 & 0.3119 & 0.0103 \\
\hline 200 & 22.7 & 23.0 & 0.2360 & 0.0104 \\
\hline 250 & 18.2 & 18.4 & 0.1898 & 0.0104 \\
\hline 500 & 9.1 & 9.2 & 0.0959 & 0.0105 \\
\hline 1000 & 4.5 & 4.6 & 0.0482 & 0.0106 \\
\hline 1500 & 3.0 & 3.1 & 0.0322 & 0.0106 \\
\hline 2000 & 2.3 & 2.3 & 0.0242 & 0.0106 \\
\hline 2500 & 1.8 & 1.8 & 0.0193 & 0.0106 \\
\hline 5000 & 0.9 & 0.9 & 0.0097 & 0.0106 \\
\hline
\end{tabular}

only can it withstand the lowering of light intensity, but the loss of operation of more than one LED, strip, or even a whole streetlight is borne without reaching-a minimum brightness that would prevent a correct view of the road [94].

For the avoidance of doubt, although all streetlight systems are strictly the same (except the one with the camera) and have all the same functions, the system cannot be considered as a parallel reliability system [95]-[97].

\section{SCALABILITY OF THE SYSTEM}

Scalability is the capability of a system or network to handle a growing amount of work or its potential to be enlarged to accommodate that growth [98].

Our system is a classic case of a system that lends itself very well to scalability. Now, we examine the strategies necessary to perform the scale-up of the system. We estimate that up to 5,000 street lamps are needed for a small city [99]. The two configurations that we will be using in the trade-off (Table 4) are quite different. In the first case, we use a single hub to connect all the groups 'IPNX8390 + LED Driver + LED Lamp' and to manage the single street lamp. In the second case, we use one hub for every five groups of street lamps. In both of the configurations, we observe how the reliability varies with the increase in the scale in terms of the number of streetlights [100]. The first line gives us the number of lamps considered in the scale-up; and the second and third return the MTBF value of the two configurations under consideration.

The last two columns illustrate the $\Delta_{\text {MTBF }}$ between the first single-hub and multi-hub configurations in both absolute and percentage terms.

We can immediately see that after 100 lamps (Figure 3), the $\Delta_{\mathrm{MTBF}}$ factor varies very little, so the reliability of the two architectures seems to be equal. This is a consideration that is incorrect in substance.

Note that after 200 lamps, the difference between the two systems remains absolutely negligible before significant changes.

From a FMECA point of view, you can see that all the lamps in the first configuration depend on only a single hub [101]. Even if the simple evaluation of the Parts Count method tells us the opposite, we immediately note that the availability of the system

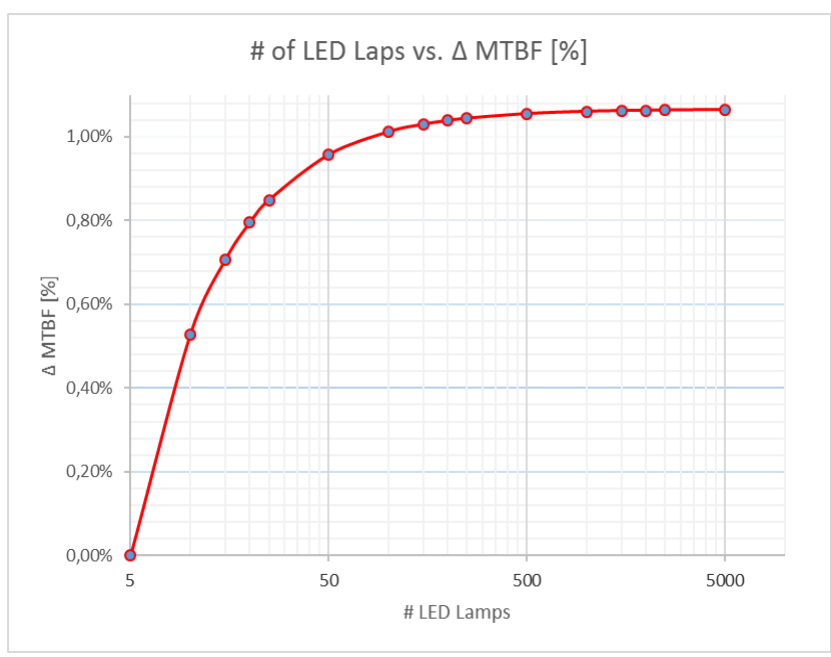

Figure 3. Number of LED lamps vs. $\Delta_{\mathrm{MTBF}}[\%]$.

is seriously compromised because a hub fail causes the switch off all the lamps. In the second configuration instead, we would have a much more modest loss of the only group of five lamps [102].

This is evidenced by the fact that the hub of the first configuration is a 'single point failure' of a critical type, which therefore entails the disastrous loss of all the functionality of the system.

\section{CONCLUSIONS}

The combination of a reliability analysis and FMECA has allowed us to manage the scale-up of the systems without needing to choose apparently reliable configurations that instead prove to be extremely vulnerable from the point of view of operational availability.

The reliability analysis was performed using the Parts Count analysis of the MIL-HDBK-217, appropriately modified to take into account several parameters (including the technological, procedural, stress, and temperature factors), in order to obtain the most realistic results for the study of the COTS components of the Smart Street system.

The FMECA helped us to identify the 'single point failure' of a configuration that proved to be suitable. In any case, one cannot ignore the "reliability analysis" in identifying the weakest and most vulnerable points. In our study, the FMECA pointed out which parts of our system need to do more stock, regardless of its reliability value.

The study of the scalability of the system shows that some critical parts (i.e. the hub) impose a 'single point failure' that could affect the functionality of the system itself. Even at the cost of raising the figure of overall reliability, it is necessary to multiply these parts in order to remove this point of singularity.

\section{REFERENCES}

[1] U.S. Department of Defense, 'Reliability prediction of electronic equipment' Tech. Rep., MIL-HDBK-217F/2, 1991.

[2] L.Gullo, 'The revitalization of MIL-HDBK-217' - IEEE Reliability Society 2008 Annual Technology Report.

[3] E. De Francesco, R. De Francesco and E. Petritoli, "Obsolescence of the MIL-HDBK-217: A critical review," 2017 IEEE International Workshop on Metrology for AeroSpace (MetroAeroSpace), Padua, 2017, pp. 282-286. doi: 10.1109/MetroAeroSpace.2017.7999581.

[4] U.S. Department of Defense, MIL-1388-2B Logistics Support Analysis Record, 
[Online] Available: http://ld.hq.nasa.gov/docs/MILSTD-13882B_DoD_Requirements.pdf [Access date: 09.05.2016].

[5] ESA Standard Document, New reliability prediction methodology aimed at space applications', Appendix 1 to $\mathrm{AO} / 1$ 8811/16/NL/PS, 12.09.2016.

[6] Radio Technical Commission for Aeronautics (RTCA), DO-160E Environmental Conditions and Test Procedures for Airborne Equipment, 2004.

[7] N.Boubekri, Technology enablers For Supply Chain Management, Integrated Manufacturing Systems 12 (2001) pp. 394-399.

[8] H. Wang et al., "Transitioning to Physics-of-Failure as a Reliability Driver in Power Electronics," in IEEE Journal of Emerging and Selected Topics in Power Electronics, vol. 2, no. 1, pp. 97-114, March 2014. doi: 10.1109/JESTPE.2013.2290282.

[9] M. Krasich, "How to estimate and use MTTF/MTBF would the real MTBF please stand up?," 2009 Annual Reliability and Maintainability Symposium, Fort Worth, TX, 2009, pp. 353-359. doi: 10.1109/RAMS.2009.4914702.

[10] Y.Song, B.Wang, Survey on reliability of power electronic systems, IEEE Trans. Power Electron. 28(1) (2013) pp. 591-604.

[11] R.Paggi, G.L.Mariotti, A.Paggi, A.Calogero, F.Leccese, 'Prognostics via physics-based probabilistic simulation approaches,' Proc. of the 2016 IEEE Metrology for Aerospace (MetroAeroSpace), $22-23$ Jun., 2016, Florence, Italy, pp. 130-135. doi: 10.1109/MetroAeroSpace.2016.7573199.

[12] Wilde, MIL-217, Bellcore/Telcordia \& Other Reliability Prediction Methods for Electronic Products' [Online] Available: http://wildeanalysis.co.uk/resource/mil-217-bellcoretelcordiareliability-prediction-methods-electronic-products/.

[13] M.Caciotta, V.Cerqua, F.Leccese, S.Giarnetti, Ett.De Francesco, Ed.De Francesco, N.Scaldarella, 'A first study on prognostic system for electric engines based on envelope analysis,' Proc. of IEEE International Workshop on Metrology for Aerospace, , 2930 May, 2014, Benevento, Italy, pp. 362-366. doi: 10.1109/MetroAeroSpace.2014.6865950.

[14] F.Adamo, G.Andria, A.Di Nisio, C.Guarnieri Calò Carducci, A.Lay-Ekuakille, G.Mattencini, M.Spadavecchia, Designing and prototyping a sensors head for test and certification of UAV components. International Journal on Smart Sensing and Intelligent Systems, 10 (2017) pp. 646-672.

[15] S.Reimann, J.Amos, E.Bergquist, J.Cole, J.Phillips, S.Shuster, "UAV for Reliability", Technical Report., University of Minnesota, Minneapolis, MN (2013). December 2013.

[16] VMEbus International Trade Association, Physics of Failure Reliability Predictions, Standard ANSI/VITA 51.2, 2011.

[17] F.Adamo, G.Andria, A.Di Nisio, C.Guarnieri Calo' Carducci, A.M.L.Lanzolla, G.Mattencini, 'Development and characterization of a measurement instrumentation system for UAV components testing', Proc. of the $4^{\text {th }}$ IEEE International Workshop on Metrology for AeroSpace, MetroAeroSpace 2017, 21-23 Jun., 2017, Padova, Italy, pp. 355-359. doi 10.1109/MetroAeroSpace.2017.799959.

[18] F.Leccese, M.Cagnetti, A.Calogero, D.Trinca, S.Di Pasquale, S.Giarnetti, L.Cozzella, 'A new acquisition and imaging system for environmental measurements: an experience on the Italian cultural heritage', Proc. of Sensors, 23 May, 2014, Basel, Switzerland, 14(5), pp. $\quad 9290-9312$. doi: 10.3390/s140509290. http://www.mdpi.com/1424-8220/14/5/9290.

[19] C.Formisano, F.Leccese, 'Procedure for the certification of spacecraft sensors: An Italian LME success history,' Proc. of 2016 IEEE Metrology for Aerospace (MetroAeroSpace), Florence, Italy, pp. 376-381. doi: 10.1109/MetroAeroSpace.2016.7573244.

[20] M.Pecht, D.Das, A.Ramarkrishnan, The IEEE standards on reliability program and reliability prediction methods for electronic equipment, Microelectron. Wearout. 42 (2002) pp. 1259-1266.

[21] R.De Francesco, E.De Francesco, F.Leccese, A.Paggi, 'The ASD S3000L for the enhancement of "in field" avionic measurements, Proc. of the IEEE International Workshop on Metrology for Aerospace, 29-30 May, 2014, Benevento, Italy, pp. 174-179. doi: 10.1109/MetroAeroSpace.2014.6865915.

[22] B.Foucher, J.Boullie, B.Meslet, D.Das, A review of reliability prediction methods for electronic devices, Microelectron. Wearout., 42(8) (2002), pp. 1155-1162.
[23] F. Nanni, S. Nacamulli, R. De Francesco and E. Petritoli, "A new reliability approach for additive layers manufactured components: A preliminary investigation," 2017 IEEE International Workshop on Metrology for AeroSpace (MetroAeroSpace), Padua, 2017, pp. 287-290. doi: 10.1109/MetroAeroSpace.2017.7999582.

[24] W. Denson, "The history of reliability prediction," in IEEE Transactions on Reliability, vol. 47, no. 3, pp. SP321-SP328, Sept. 1998. doi: $10.1109 / 24.740547$

[25] R.H.Kolbe, M.S.Burnett, Content-analysis research: an examination of applications with directives for improving research reliability and objectivity, J. Consum. Res. 18(2) (1991) pp. 243250. doi: https://doi.org/10.1086/209256.

[26] Ed.De Francesco, Ett.De Francesco, R.De Francesco, F.Leccese, M.Cagnetti, 'A proposal to update LSA databases for an operational availability based on autonomic logistic,' Proc. of the $2^{\text {nd }}$ IEEE International Workshop on Metrology for Aerospace, 3 5 Jun., 2015, Benevento, Italy, pp. 38-43. doi: 10.1109/MetroAeroSpace.2015.7180623.

[27] IEEE Standard Framework for the Reliability Prediction of Hardware, IEEE Standard 1413, 2009.

[28] E. Petritoli, F. Leccese and L. Ciani, "Reliability assessment of UAV systems," 2017 IEEE International Workshop on Metrology for AeroSpace (MetroAeroSpace), Padua, 2017, pp. 266-270. doi: 10.1109/MetroAeroSpace.2017.7999577.

[29] X.Perpinya, 'Reliability and safety in railways', Proc. of InTech, 2012, Rijeka, Croatia, ch. 7 pp. 601-615. DOI: 10.5772/2660

[30] H.Wang, K.Ma, F.Blaabjerg, 'Design for reliability of power electronic systems,' in Proc. of the 38 th Annu. Conf. IEEE Ind. Electron. Soc., Oct., 2012, pp. 33-44.

[31] R.Paggi, G.L.Mariotti, A.Paggi, F.Leccese, 'Optimization of availability operation via simulated prognostics,' Proc. of the $2^{\text {nd }}$ IEEE International Workshop on Metrology for Aerospace, 4-5 Jun. 2015, Benevento, Italy, pp. 44-48. doi: 10.1109/MetroAeroSpace.2015.7180624.

[32] J.G.W.Wildenbeest, D.A., Abbink, C.J.M., Heemskerk, F.C.T.Van Der Helm, H.Boessenkool, The impact of haptic feedback quality on the performance of teleoperated assembly tasks, IEEE Transactions on Haptics, 6(2) (2013) pp. 242, 252.

[33] F.Marino, F.Leccese, S.Pizzuti, Adaptive street lighting predictive control Energy Procedia, 111 (2017) pp. 790-799. doi: 10.1016/j.egypro.2017.03.241E.

[34] E. Petritoli and F. Leccese, "Reliability andSEE mitigation in memories for space applications," 2016 IEEE Metrology for Aerospace (MetroAeroSpace), Florence, 2016, pp. 136-140. doi: 10.1109/MetroAeroSpace.2016.7573200.

[35] M.G.Pecht and F. R. Nash, "Predicting the reliability of electronic equipment," in Proceedings of the IEEE, vol. 82, no. 7, pp. 992 1004, July 1994. doi: $10.1109 / 5.293157$.

[36] G.Andria, F.Attivissimo, A.Di Nisio, A.M.L.Lanzolla, A.Pellegrino, Development of an automotive data acquisition platform for analysis of driving behavior. Measurement 93 (2016) pp. 278-287, doi: 10.1016/j.measurement.2016.07.035

[37] M.Caciotta, V.Cerqua, F.Leccese, S.Giarnetti, Ett.De Francesco, Ed.De Francesco, N.Scaldarella, 'A first study on prognostic system for electric engines based on envelope analysis', Proc. of the IEEE International Workshop on Metrology for Aerospace, 29-30 May, 2014, Benevento, Italy, pp. 362-366. doi: 10.1109/MetroAeroSpace.2014.6865950.

[38] E.Balestrieri, L.De Vito, F.Lamonaca, F.Picariello, S.Rapuano, I.Tudosa, "Research challenges in measurements for Internet of Things systems", ACTA IMEKO, 2018, vol 7, N. 4, pp.82 - 94.

[39] D.Duarte, N. Vijaykrishnan, M. J. Irwin, H. -. Kim and G. McFarland, "Impact of scaling on the effectiveness of dynamic power reduction schemes," Proceedings. IEEE International Conference on Computer Design: VLSI in Computers and Processors, Freiberg, Germany, 2002, pp. 382-387. doi: 10.1109/ICCD.2002.1106798.

[40] K.J.Kuhn et al., Process technology variations, IEEE Trans. Elect. Dev. 58(8) (2011) pp. 2197-2208.

[41] P.Lall et al., Leading indicators of failure for prognostication of leaded and lead-free electronics in harsh environments, IEEE Trans. Comp. and Packaging Technology 32(1) (2009) pp. 135-144.

[42] S.Manson, Thermal Stress and Low Cycle Fatigue, McGraw-Hill, New York, 1966 ISBN-13: 978-0070399303. 
[43] J.Srinivasan, S. V. Adve, P. Bose and J. A. Rivers, "The impact of technology scaling on lifetime reliability," International Conference on Dependable Systems and Networks, 2004, Florence, Italy, 2004, pp. 177-186. doi: 10.1109/DSN.2004.1311888.

[44] JEDEC Document JEP122E, Failure Mechanisms and Models for Semiconductor Devices, March 2009.

[45] EEE-INST-002: Instructions for EEE Parts Selection, Screening, Qualification, and Derating NASA/TP-2003-212242.

[46] M.Talmor, M. Talmor and S. Arueti, "Reliability prediction: the turn-over point," Annual Reliability and Maintainability Symposium, Philadelphia, PA, USA, 1997, pp. 254-262. doi: 10.1109/RAMS.1997.571717.

[47] I.Bazovsky, Reliability Theory and Practice, Prentice-Hall Inc, Englewood Cliffs, N.J. : Prentice-Hall, 1961. Book ID 001512021AU.

[48] Naval Surface Warfare Center - Carderock Division, Handbook of Reliability Prediction Procedure for Mechanical Equipment, CARDEROCKDIV, NSWC-07, Sept. 2007.

[49] S.R.Calabro, B.G.Horowitz, "Evaluation equipment reliability using techniques based on kappa square statistics", 2009 8th International Conference on Reliability, Maintainability and Safety, Chengdu, 2009, pp. 1062-1065. doi: 10.1109/ICRMS.2009.5269997.

[50] F.Zhao, Z.Tian, E.Bechoefer, Y.Zeng, An integrated prognostic method under time-varying operating condition, IEEE Trans. On Reliability 64(2) (2015) pp. 673-686.

[51] L.Liao, F.Kottig, Review of hybrid prognostic approach for remaining useful life prediction, IEEE Trans. on Reliability 63(1) (2014) pp. 191-207.

[52] R. E. Barlow, "A Bayes Explanation of an Apparent Failure Rate Paradox," in IEEE Transactions on Reliability, vol. R-34, no. 2, pp. 107-108, June 1985. doi: 10.1109/TR.1985.5221964).

[53] U.S. Department of Defense, MIL-STD-810F, Environmental Engineering Considerations and Laboratory Tests (Revision F) 2000 .

[54] F.O.Ehiagwina, O.T.Adewunmi, O.O.Bamigboye, E.O.Seluwa Determination of the reliability of a locally made clap activated switch by part count analysis, International Journal of Engineering and Applied Science 5(1) (2016) pp. 62-71.

[55] E. Petritoli, F. Leccese, M. Botticelli, S. Pizzuti and F. Pieroni, "'Smart Street" Pilot Site: A RAMS Analysys for a ScaleUpconfiguration," 2018 Workshop on Metrology for Industry 4.0 and IoT, Brescia, 2018, pp. 129-133. doi: 10.1109/METROI4.2018.8428338.

[56] Telecordia, Reliability Prediction Procedure for Electronic Equipment, Issue 2, 2006.

[57] L.. Zhou, R. Cao, C. Qi and R. Shi, "Reliability prediction for smart meter based on Bellcore standards," 2012 International Conference on Quality, Reliability, Risk, Maintenance, and Safety Engineering, Chengdu, 2012, pp. 631-634. doi: 10.1109/ICQR2MSE.2012.6246312.

[58] J. Kim, S. Choi and K. Lee, "Reliability Prediction Approach of DC-DC Converter with Electrical Stress Analysis," CIPS 2014; 8th International Conference on Integrated Power Electronics Systems, Nuremberg, Germany, 2014, pp. 1-4. URL: http:/ /ieeexplore.ieee.org/stamp/stamp.jsp?tp= \&arnumber $=677$ 6798\&isnumber $=6776778$.

[59] L.Bechou, Y. Deshayes, Y. Ousten, O. Gilard, G. Quadri and Lip Sun How, "Monte-carlo computations for predicted degradation of photonic devices in space environment," 2015 IEEE Aerospace Conference, Big Sky, MT, 2015, pp. 1-16. doi: 10.1109/AERO.2015.7119012.

[60] ITEM Software and Reliasoft Corporation, RS 490 Course Notes: Introduction to Standards Based Reliability Prediction and Lambda Predict, 2006.

[61] G.Schirripa Spagnolo, D.Papalillo, F.Leccese, 'Forensic metrology: uncertainty of measurements in forensic analysis', Proc. of the $20^{\text {th }}$ IMEKO TC-4 International Symposium Measurement of Electrical Quantities, 15-17 Sept., 2014, Benevento, Italy.

[62] D.L.Carni, D.Grimaldi, F.Lamonaca, L.Nigro, P.F.Sciammarella, "From distributed measurement systems to cyber-physical systems: A design approach", Computing International Scientific Journal, vol. 16, 2017, p. 66-73.
[63] R.German, A. Sari, P. Venet, Y. Zitouni, O. Briat and J. Vinassa, "Ageing law for supercapacitors floating ageing," 2014 IEEE 23rd International Symposium on Industrial Electronics (ISIE), Istanbul, 2014, pp. 1773-1777. doi: 10.1109/ISIE.2014.6864883.

[64] M.Musallam, C.Yin, C.Bailey, M.Johnson, Mission profile-based reliability design and real-time life consumption estimation in power electronics, IEEE Transactions on Power Electronics 30(5) (2015) pp. 2601-2613.

[65] N.Sakr, N.D.Georganas, Z.Jiying, Human perception-based data reduction for haptic communication in six-DoF telepresence systems, IEEE Transactions on Instrumentation and Measurement 60(11) (2011) pp. 3534-3546.

[66] D.Fan, Y. Ren, Z. Wang and L. Liu, "Mission reliability prediction methods for board-level electronic equipment based on physics of failure and Bayesian networks," 2015 First International Conference on Reliability Systems Engineering (ICRSE), Beijing, 2015, pp. 1-7. doi: 10.1109/ICRSE.2015.7366465.

[67] G. Bacis, M. Catelani, L. Ciani, V. Scarano and R. Singuaroli, "A novel approach to thermal tests for flash memories reliability improvement based on DoE method," 2007 IEEE Instrumentation \& Measurement Technology Conference IMTC 2007, Warsaw, 2007, pp. 1-4. doi: 10.1109/IMTC.2007.379240.

[68] G.Andria, E.Di Sciascio, A.Lay-Ekuakille, A.Lanzolla, M.Ruta, 'Kalman-Kriging technique applied to space-aided distributed sensor system to manage critical environmental events', Proc. of the IEEE Metrology for Aerospace, MetroAeroSpace 2016, 22-23 Jun., 2016, Firenze, Italy, pp. 418-422. doi: 10.1109/MetroAeroSpace.2016.7573252.

[69] M. Catelani, L. Ciani and M. Venzi, "RBD Model-Based Approach for Reliability Assessment in Complex Systems," in IEEE Systems Journal. doi: 10.1109/JSYST.2018.2840220.

[70] M.Catelani, L.Ciani, L.Signorini, G.Barile, 'TFT-LCD for avionics applications: development, characterization and reliability analysis', Proc. of I2MTC 2010 (IEEE - International Instrumentation And Measurement Technology Conference), May, 2010, Austin, Texas, pp. 647-651.

[71] K Hausler, B. Sumpf, G. Erbert and G. Trankle, "Degradation Analysis of $808 \mathrm{~nm}$ GaAsP Laser Diodes," 2007 Conference on Lasers and Electro-Optics - Pacific Rim, Seoul, 2007, pp. 1-2. doi: 10.1109/CLEOPR.2007.4391194.

[72] Y.Ren, Q.Feng, T.Ye, B.Sun, A novel model of reliability assessment for circular electrical connectors, IEEE Transactions on Components, Packaging, and Manufacturing Technology 6(5) (2015) pp. 755-761.

[73] A.Kerber, W.McMahon, E.Cartier, Voltage ramp stress for hotcarrier screening of scaled CMOS devices, IEEE Electron Device Letters 30(6) (2012) pp. 749-751.

[74] A.Zaka, P.Palestri, Q.Rafhay, R.Clerc, M.Iellina, D.Rideau, C.Tavernier, G.Pananakakis, H.Jaouen, L.Selmi, An efficient nonlocal hot electron model accounting for electron: electron scattering, IEEE Transactions on Electron Devices 59(4) (2012) pp. 983-993.

[75] F.Zarate-Rincon, D.Garcia-Garcia, V.VegaGonzalez, R.TorresTorres, R.MurphyArteaga, Characterization of hot-carrier induced RF-MOSFET degradation at different bulk biasing conditions from parameters, IEEE Transactions on Microwave Theory and Techniques 65(1) (2016) pp. 125-132.

[76] W. Li and C. M. Tan, "Black's equation for today's ULSI interconnect Electromigration reliability — A revisit," 2011 IEEE International Conference of Electron Devices and Solid-State Circuits, Tianjin, 2011, pp. 1-2. doi: 10.1109/EDSSC.2011.6117717.

[77] R. Labie et al., "Electromigration failure mechanisms for different flip chip bump configurations," 2011 International Reliability Physics Symposium, Monterey, CA, 2011, pp. 5F.4.1-5F.4.5. doi: 10.1109/IRPS.2011.5784541.

[78] R.De Orio, S.Selberherr, 'Physically based models of electromigration', Proc. of the 2013 IEEE International Conference of Electron Devices and Solid-State Circuits (EDSSC), 2013.

[79] M.Catelani, L.Ciani, G.Barile, A new design technique of TFTLCD display for avionics application, Microelectronics Reliability 52(9-10) (2012) pp. 1776-1780. 
[80] D.G. Zeng, K.-i.Lee, K.-w.Chung, S.Bae, Electromigration in giant magnetoresistance spin valve read sensors under pulsed DC magnetic field: an analytical and numerical study, IEEE Transactions on Magnetics 49(2) (2013) pp. 845-850.

[81] Xin Huang, Tan Yu, V. Sukharev and S. X. -. Tan, "Physics-based electromigration assessment for power grid networks," 2014 51st ACM/EDAC/IEEE Design Automation Conference (DAC), San Francisco, CA, 2014, pp. 1-6. doi: 10.1145/2593069.2593180.

[82] Y. Xu, L. Huang, G. Chen, F. Wu, W. Xia and H. Liu, "Electromigration - Induced failure mechanism and lifetime prediction in NiCu thin film," 2014 15th International Conference on Electronic Packaging Technology, Chengdu, 2014, pp. 1071 1074. doi: 10.1109/ICEPT.2014.6922831.

[83] M.Rovitto, W.Zisser, H.Ceric, 'Analysis of electromigration void nucleation failure time in open copper TSVs', Proc. of the 2015 IEEE 22nd International Symposium on the Physical and Failure Analysis of Integrated Circuits (IPFA), 2015.

[84] S.Jacques, A.Caldeira, N.Batut, A.Schellmanns, R.Leroy, L.Gonthier, 'A Coffin-Manson model to predict the TRIAC solder joints fatigue during power cycling', Proc. of the 2011-14th European Conf. on Power Electronics and Applications (EPE 2011), 2011, Birmingham UK, pp 740-753.

[85] A.Testa, S.De Caro, S.Russo, A reliability model for power MOSFETs working in avalanche mode based on an experimental temperature distribution analysis, IEEE Transactions, Power Electronics 27(6) (2011) pp. 3093-3100.

[86] M. Catelani, A. Zanobini, L. Ciani and F. Corsini, "Qualification tests and reliability analysis on electronic ballast system," 2009 IEEE Instrumentation and Measurement Technology Conference, Singapore, 2009, pp. 1707-1710. doi: 10.1109/IMTC.2009.5168731.

[87] G.Andria, A.Di Nisio, V.L.Scarano, M.Spadavecchia, M.Bregoli, M.Franceschi, N.Tavernini, 'Accelerated life tests of a new optocoupler for aerospace application', Proc. of the 2014 IEEE International Workshop on Metrology for Aerospace, MetroAeroSpace, 29-30 May, 2014, Benevento, Italy, pp. 510-514. doi: 10.1109/MetroAeroSpace.2014.6865978.

[88] S.Paneels, J.C.Roberts, Review of designs for haptic data visualization, IEEE Transactions on Haptics 3(2) (2010) pp. 119137.

[89] C.Junhua, Z.Jiping, S.Yan, Z.Lixin, 'Fatigue life predicting of leadfree soldered joints of QFP device', Proc. of the 2012 International Conference on Computer Science \& Service System (CSSS), 2012.

[90] G. Smith, J. B. Schroeder, S. Navarro and D. Haldeman, "Development of a prognostics and health management capability for the Joint Strike Fighter," 1997 IEEE Autotestcon Proceedings AUTOTESTCON '97. IEEE Systems Readiness Technology Conference. Systems Readiness Supporting Global Needs and Awareness in the 21st Century, Anaheim, CA, USA, 1997, pp. 676682. doi: 10.1109/AUTEST.1997.643994.
[91] M.A.Neidigk, S.Yu-Lin, 'Predicting the effect of underfill filler volume fraction on solder fatigue life and residual stress for surface mount components using nonlinear viscoelastic analyses, IEEE Transactions on Components, Packaging and Manufacturing Technology 2(9) (2012) pp. 1492-1500.

[92] H.-C.Cheng, Y.-M.Tsai, S.-T.Lu, W.-H.Chen, Interconnect reliability characterization of high-density 3D chip-on-chip interconnect technology, IEEE Transaction on Components, Packaging and Manufacturing Technology 3(12) (2013) pp. 20372047.

[93] T.Happonen, T.Ritvonen, P.Korhonen, J.Hakkinen, T.Fabritius, Modeling the lifetime of printed silver conductors in cyclic bending with the Coffin-Manson relation, IEEE Transactions on Device and Materials Reliability 16(1) (2016) pp.25-29.

[94] B.Zhang, G.Tao, "An improved CoffinManson model for midpower LED wirebonding reliabilty", Proc. of the 2014 IEEE 21st International Symposium on the Physical and Failure Analysis of Integrated Circuits (IPFA) Marina Bay Sands, 2014 27(6) (2011) pp. 3093-3100.

[95] J.-S.Huang, Reliability-extrapolation methodology of semiconductor laser diodes: is a quick life test feasible? IEEE Transactions on Device and Materials Reliability 6(1) (2006) pp. 46-51.

[96] L.Han, N.Narendran, An accelerated test method for predicting the useful life of an LED driver, , IEEE Transactions on Power Electronics 26(8) (2011) pp. 2249-2257.

[97] T.Adithya, K.V.Ajit, K.Uday, Comparison of failure characteristics of different electronic technologies by using modified physics-offailure approach, International Journal of System Assurance Engineering and Management 6(2) (2015) pp. 198-205.

[98] M.Catelani, L.Ciani, G.Barile, 'Design and reliability assessment of an avionics tft-lcd display', Proc. of the XX IMEKO World Congress - Metrology for Green Growth, 9-14 Sep., 2012, Busan, Rep. of Korea, pp. 592-596.

[99] S. Kaminani and R. Collins, "Touch screen technology in flight deck, how far is it helpful?," 2012 IEEE/AIAA 31st Digital Avionics Systems Conference (DASC), Williamsburg, VA, 2012, pp. 2D3-1-2D3-5. doi: 10.1109/DASC.2012.6382292.

[100] S.Kaminani, 'Human computer interaction issues with touch screen interfaces in the flight deck,' Proc. of the 2011 IEEE/AIAA 30th Digital Avionics Systems Conference (DASC), 16-20 Oct., 2011, pp.6B4-1,6B4-7.

[101] N.Sakr, N.D.Georganas, Z.Jiying, Human perception-based data reduction for haptic communication in six-DoF telepresence systems, IEEE Transactions on Instrumentation and Measurement, 60(11) (2011) pp.3534-3546.

[102]D. L. Carnì, D. Grimaldi, F. Lamonaca, L. Martirano and G. Parise, "A smart control to operate the lighting system in the road tunnels," 2013 IEEE 7th International Conference on Intelligent Data Acquisition and Advanced Computing Systems (IDAACS), Berlin, 2013, pp. 786-790. doi: 10.1109/IDAACS.2013.6663033 